\title{
The Impact of Vocabulary Enhancement Activities on Vocabulary Acquisition and Retention among Male and Female EFL Learners in Iran
}

\author{
Maryam Sharafi-Nejad ${ }^{1}$, Shohreh Raftari ${ }^{2}$, Maryam Bijami ${ }^{3}$, Zahra Khavari ${ }^{4}$, Shaik Abdul Malik Mohamed \\ Ismail $^{1} \&$ Lin Siew Eng ${ }^{1}$ \\ ${ }^{1}$ School of Educational Studies, UniversitiSains Malaysia (USM), Malaysia \\ ${ }^{2}$ English Department, Kerman Branch, Islamic Azad University, Kerman, Iran \\ ${ }^{3}$ School of Languages, Literacies and Translation, University Sains Malaysia, Malaysia \\ ${ }^{4}$ Payame Noor University, Qeshm International Branch, Iran \\ Correspondence: Maryam Sharafi-Nejad, School of Educational Studies, Universiti Sains Malaysia, 11800, \\ Penang, Malaysia. Tel: 601-2285-7517.E-mail: msn12_edu085@student.usm.my
}

\author{
Received: January 6, 2014 Accepted: February 10, 2014 Online Published: March 6, 2014 \\ doi:10.5539/elt.v7n4p126 URL: http://dx.doi.org/10.5539/elt.v7n4p126
}

\begin{abstract}
In general, incidental vocabulary acquisition is represented as the "picking up" of new vocabularies when students are engaged in a variety of reading, listening, speaking, or writing activities. Research has shown when learners read extensively incidental vocabulary acquisition happens. Many EFL students cannotbe involved in reading activities in Iran. For involving students with more reading activitiesin EFL classroom teaching and likening the resultsto the vocabulary exercises, the researcher directed a researchfor about five weeks in an EFL class. The subjects were 120 male and female students at high school level. Half of them (RP group) read chosen passages after which they did different vocabulary activities and exercises. The other half (RO group) received the reading only (RO) treatment, i.e., they only read several reading texts. The significance of the present study lies in the fact that it was able to compare the effectiveness of reading only and reading plus vocabulary enhancement activities on types of immediate and delayed lexical word recall in a single study. The researcher employed the Vocabulary Knowledge Scale to measure students' knowledge of 60 vocabulary items. The results showed that RP group gained better results than RO group on both acquisition and retention tests. This indicates that "Reading plus" method is more effective in increasing knowledge of vocabulary and long term retention in male and female EFL learners in Iran.
\end{abstract}

Keywords: vocabulary acquisition, vocabulary retention, extensive reading, EFL learners, Iran

\section{Introduction}

In the study of English language teaching and learning, a continual problem has been the overlook of learning vocabulary. This problem was often given little superiority in language literature and was often left to look after itself and received only inessential attention in language programs (Hedge, 2008; Richards \& Renandya, 2002). Folse (2004) states that "it is a story to say that acquisition of vocabulary is not as fundamental as learning grammar or the other parts of language, when there is a reality that learning vocabulary has a very essential function in English language learning" (Chen \& Chun, 2008; Shoebottom, 2007). This is because the more words they know, the more able the students are in understanding what they hear and read, so the better students have the ability to say what they need while speaking or writing the target language (Shoebottom, 2007). In addition, learning vocabulary of second or foreign language (L2/FL) and first language (L1) is not similar. Folse (2004) asserts that dissimilar to learning L1 vocabulary, L2 learners require acquiring the form, the meaning, and the usage of the word that can be attained by doing different classroom activities. Wilkins $(1972$, as cited in Herbertson, 2010) explains the significance of learning vocabulary in his quote, "Without grammar, very little can be conveyed, without vocabulary nothing can be conveyed." The explanation demonstrates that someone's efforts to communicate his/her meaning to others could be of no help without lexis. Nevertheless, a meaning could still be understood in spite of usinggrammatically incorrect sentences. However, problems might happen if 
one does not know the accurate word to interpret meanings. The explanation also imposes that nobody is able to read or listen without the knowledge of vocabulary (Herbertson, 2010).

\section{Literature Review}

Context plays an important role in learning vocabulary. Although, oral language is necessary to be manipulated too, normally, written language has a higher rate of difficult or low frequency words. As a result, the effective practical way for continual vocabulary learning is reading (Nagy, Herman, \& Anderson, 1985; Nation \& Coady, 1988). As we know, there are many different ways of teaching and demonstrating vocabulary through reading texts, of which, incidental learning is one (Richards \& Renandya, 2002; Hatch \& Brown, 1995). Coady (1997a, p. 275) calls this method (incidental learning) "context alone" as "the first position on the continuum is labeled context alone. It proposes that there is actually no need or even justification for direct vocabulary instruction". This statement of Coady (1997a) is based on Krashen's (1989) view, that students can gain all the vocabularies they want from the text if they can understand the text with success. Extensive reading can lead to greater vocabulary development than one program of explicit instruction alone, thus teachers should be more aware of it and direct more focus toward it (Coady, 1997a; Nagy, Herman, \& Anderson, 1985).

However, some researchers say that it is necessary to have repeated exposure to new words. Chun and Plass (1996, p.184) asserted that "the research on learning words in context found only $5-15 \%$ probability that a given word would be learned at first exposure". What's more, many researchers accept the usefulness of explicit teaching of vocabulary or reading plus vocabulary enhancement activities and do not believe in the efficiency of context alone method (Coady \& Huckin, 1997). Lyster (1990) and Swain (1988) state that improvement in context alone method is slow and random so they say no to the efficiency of this method. Nation and Coady (1988, p. 101) state that "it is the very redundancy or richness of information in a given context which enables a reader to guess an unknown wordsuccessfully or could also predict that the same reader is less likely to learn the word because he or she was able to comprehend the text without knowing the word". Paribakht and Wesche (1993) determined that many studentsdid not check the meaning of unknown words in reading texts unless reading comprehension questions particularly needed them to be comprehended.

\subsection{Research Questions}

1) Do Iranian EFL learners gain more vocabulary knowledge through reading plus supplemental vocabulary activities than reading additional texts with the same words? If yes, are the words retained after three months?

2) Do Iranian male and female EFL learners perform significantly different in learning vocabulary through these methods in immediate acquisition and retention after three months period?

\section{Methodology}

\subsection{Participants}

120 male and female students studying at Shariat and Marefat High-SchoolsinKerman (a city in south-east Iran) participated in this study. Their agesranged from 16 to 18 and their native language was Farsi. All of the students had learned English in school for five years before the classroom-based experiment. A Nelson test (Norman and Fowler, 1986) was administered to 200 students and 120 students with the same level of EFL proficiency were chosen who were divided into four groups of 30 ( 2 male and 2 female groups). The Nelson test was administered to find out groups' homogeneity to determine that the four groups' English proficiency was at the same level before the instruction.

\subsection{Study Design}

At the beginning of instructional treatments, all of the students received the class program that explained the activities and dates of the class. Theclass took place two hours a week which was 10 hours for a total of five weeks. To ensure students' lack of knowledge about the vocabularies, the target words which were sixty lexical items were pilot-tested with another 120 students with the same English language proficiency. The participants took a pretest before the formal instruction. They took a posttest after 10 hours instruction, and finally took a delayed posttest after three month. At the end, there were 7200 words to score at each test.

\subsection{Administration Procedures}

There were four groups, one RO and one RP in males, one RO and one RP in females. In both of the groups (RP and RO) students read the selected texts and answered the following comprehension questions. However, in the RP group, after answering the comprehension questions, students did some vocabulary exercises on the target words from the texts. But in the RO group, students read a supplementary text to present again the vocabularies from the main text instead of doing vocabulary exercises after answering the comprehension questions. 


\subsection{Reading Materials}

Two main passages were used in this study. The two passages were taken from the book "English (3)"of Iranian high schools. Reading materials were based on instructional appropriateness, students' interest, text length and linguistic difficulty. The first passage' stitle was Computer Culture, comprising of 6 paragraphs, and the secondone's title was Future of Medicine, comprising of 7paragraphs. Two weeks before the study, words were pre-tested to check their novelty, and the familiar words were omitted.

As the thematically-related supplemental materials, there were two other passages, one on Unmasking Virus Writers and Hackers and the other one on Robotic Surgeons, incorporating the same words. The supplemental materials were collected by the researcher and edited by a native English speaker for the RO group. The supplemental materials were for exposing the students to the target words again and ensuring that students had more encounter with vocabularies during reading.

\subsection{Pilot Study}

A pilot study was conducted in the winter to field-test the materials and procedures. Subjects in the pilot study were 60 female students studying at pre-university level. There were two main reading texts and two supplementary reading texts for 60 treatment words. T-test on the data revealed significant gains on the RP treatment. This limited evidence suggested that vocabulary enhancement techniques were effective in increasing the learning of selected words. A longer study of this phenomenon was thus undertaken.

\subsection{Test Instrument}

To test the students' vocabulary knowledge, the researcher used the Vocabulary Knowledge Scale developed by Paribakht and Wesche (1997) to measure vocabulary knowledge and retention. This instrument uses a score of one to five points for each subject's self-analysis of each target word. The scoring criteria were explained as follows:

(1) One point is given for words reported both unfamiliar and unknown.

(2) Two points are given for familiar words with unknown meanings.

(3) Three points are given if a synonym or translation of the target word is correct.

(4) Four points are given when the use of a word is semantically correct.

(5) Five points are given when the use of a target word is both grammatically and semantically correct, even if other parts of the sentence contain errors.

\subsection{Data Analysis}

After giving the tests, the scores were gathered in the form of raw data for data analysis. They were then illustrated through descriptive statistics, andthe central tendencies and variability measurements were applied to the scores after the post and delayed posttests were administered. Then, the results were compared by using a one way ANOVA Test in both treatments in male and female participants' tocheck which method wasbetter for vocabulary acquisition and retention after three months and specifying whether there existed any significant difference between males and females in acquisition and retention of vocabularies via these methods. The data collected from the participants were analyzed using Statistical Package for the Social Science (SPSS), version 16.00 and Microsoft office Excel.

\section{Results and Discussion}

The significance of the present study lies in the fact that the researcher wished tocompare the effectiveness of reading only and reading plus vocabulary enhancement activities on types of immediate and delayed lexical word recall in a single study. The researcher employed the Vocabulary Knowledge Scale to measure students' knowledge of 60 vocabulary items. Specifically, the researcher wanted to find the impacts of each instructional treatment $(\mathrm{RO}$ and $\mathrm{RP})$ on vocabulary acquisition and retention.

Therefore, the following questions were addressed in this study:

1) Do Iranian EFL learners gain more vocabulary knowledge through reading plus supplemental vocabulary activities than reading additional texts with the same words? If yes, are the words retainedafter three months?

2) Do Iranian male and female EFL learners perform significantly different in learning vocabulary through these methods (RP vs. RO) in immediate acquisition and retention after three months period?

At first, the participants took a pretest before the formal instruction. After the treatment and the completion of its different phrases, in the period of 10-hours instruction, the subjects took their post-tests, which consisted of 60 
items covering the vocabulary exposed to them. They afterwards took a delayed posttest after 3 months. At the end, the tests were scored, and applying a one way ANOVA Test was decided to be the proper statistical computation to compare the results of these two methods, i.e., RP and RO on vocabulary acquisition and retention in male and female Iranian EFL learners and specifying whether there existed any significant difference between the results of male and female participants in acquisition and retention tests or not.

To answer the first research question, a one way ANOVA Test was conducted to examine the differences between the two methods in male and female students. Both male and female groups served as their own controls. The results showed that the RP group gained more vocabularies after the instructional treatment in both male and female groups. The students acquired more vocabulariesbased on the results of the mean differences between the RP groups' acquisition and pretest scores in male $(\mathrm{MD}=102)$ and female $(\mathrm{MD}=101.5)$ participants after instruction (Appendix A). In addition, the RP group still remembered more vocabularies 3months after the instructional treatment than they did before receiving instruction based on the mean differences between retention and pretest scores in males $(\mathrm{MD}=59.3)$ andfemales $(\mathrm{MD}=58.8)$, although they forgot many vocabularies as illustrated by the mean difference between their acquisition and retention scores in males $(\mathrm{MD}=-42.7)$ and $(\mathrm{MD}=-42.7)$ in females (Appendix A).

Similar to the RP groups, RO groups also acquired many vocabularies after reading supplementary materials $(\mathrm{MD}=82.5)$ in males and $(\mathrm{MD}=82.6)$ in females, though far less than the RP groups' amount of vocabulary acquisition and retension. Inaddition, the RO group still remembered more vocabularies 3 months after the instruction than they did before receiving the instruction based on the mean differences between retention and pretest scores in males $(\mathrm{MD}=42.8)$ and $(\mathrm{MD}=43.1)$ in females; although, they also forgot many vocabularies as illustrated by the mean differencesbetween their acquisition and retention scores in males $(\mathrm{MD}=-39.7)$ and in females $(\mathrm{MD}=-39.5)$. These results that students acquired vocabularies through both of methods (RPand RO) corroborated the previous literature (Laufer, 2003; Paribakht \& Wesche, 1997; Rott, 1999). According to the results, students had ability to remember some vocabularies after three months in both groups. The findings further suggested the long-term effect of these two methods because the words that studentsretained after three months were more than the ones before the instructional treatments.

For the first research question, the researcher ran an "independent one way ANOVA Test" to find out which instructional treatment is better (RP or RO) for vocabulary acquisition and retention. As illustrated in (Appendix A), knowledge of the students about the 60 target vocabularies was not significantly different in RP and RO groups before the instructional treatment based on the mean differences in males $(M D=-5)$ and in females $(M D=-4.4)$. After the instruction; however, the RP groups gained more vocabularies than the RO method groups in male and female students based on the mean differences between RP and RO that was $(M D=14.5)$ in males and $(M D=14.5)$ in females at acquisition test that was significant. Three months after the instruction, the RP group still retained significantly more vocabularies than the RO group in male and female students based on the mean difference between RP and RO scores $(\mathrm{MD}=11.5)$ in males and $(\mathrm{MD}=11.3)$ in females at the retention testgiven 3 months after the instruction indicating significant differences.

Table 1. Test of homogeneity of variances

\begin{tabular}{lccc}
\hline Levene Statistic & $\mathrm{df1}$ & $\mathrm{df2}$ & Sig. \\
\hline .293 & 3 & 116 & .830 \\
\hline
\end{tabular}

Table 2. Results of ANOVA test on the pretest scores

\begin{tabular}{lccccc}
\hline & Sum of Squares & df & Mean Square & F & Sig. \\
\hline Between Groups & 810.600 & 3 & 270.200 & .345 & .793 \\
Within Groups & 90789.400 & 116 & 782.667 & & \\
Total & 91600.000 & 119 & & & \\
\hline
\end{tabular}

According to the results of table 1, significance of Levene's Statisticswas 0.830 (sig $>0.05)$ in pre-test, so the test of the comparison of means with the assumption of homogeneity of variances was performed whose results were shown in Table 2. The significance between the treatment groups (RP and RO) on the pretest scores was .793 ( $\mathrm{sig}>0.05)$, so there existed no significant difference between groups on the pretest scores (Table 2 ). 
Table 3. Test of homogeneity of variances

\begin{tabular}{lccc}
\hline Levene Statistic & df1 & df2 & Sig. \\
\hline 1.014 & 3 & 116 & .389 \\
\hline
\end{tabular}

Table 4. Results of ANOVA test on the acquisition scores

\begin{tabular}{lccccc}
\hline & Sum of Squares & df & Mean Square & F & Sig. \\
\hline Between Groups & 6427.500 & 3 & 2142.500 & 2.958 & .035 \\
Within Groups & 84005.800 & 116 & 724.188 & & \\
Total & 90433.300 & 119 & & & \\
\hline
\end{tabular}

The significance of Levene's Statistic was 0.389 ( $\mathrm{sig}>0.05$ ) in acquisition test (table 3 ), thusthe test of comparison of means with the assumption of homogeneity of variances was performed (Table 4). The significance between groups (RP and RO) on the acquisition scores was 0.035 ( $\mathrm{sig}<0.05)$, so there existed a significant difference between groups on the acquisition scores (Table 4); therefore, the hypothesis of homogeneity of means at 0.05 level was rejected, i.e., at least two groups out of the four participating groups in the present study had different means; as a result, for specifying the groups which hadsignificantly different means, LSD Test was performed (Table 5).

Table 5. LSD test for the acquisition scores

\begin{tabular}{lcccccc}
\hline \multirow{2}{*}{ (I) Groups } & (J) Groups & Mean Difference (I-J) & Std. Error & Sig. & \multicolumn{2}{c}{$95 \%$ Confidence Interval } \\
\cline { 5 - 7 } RP Male & RP Female & -2.00000 & 6.94832 & .774 & -15.7620 & 11.7620 \\
& RO Male & $14.50000^{*}$ & 6.94832 & .039 & .7380 & 28.2620 \\
& RO Female & 12.50000 & 6.94832 & .075 & -1.2620 & 26.2620 \\
\hline \multirow{2}{*}{ RP Female } & RP Male & 2.00000 & 6.94832 & .774 & -11.7620 & 15.7620 \\
& RO Male & $16.50000^{*}$ & 6.94832 & .019 & 2.7380 & 30.2620 \\
& RO Female & $14.50000^{*}$ & 6.94832 & .039 & .7380 & 28.2620 \\
\multirow{2}{*}{ RO Male } & RP Male & $-14.50000^{*}$ & 6.94832 & .039 & -28.2620 & -.7380 \\
& RP Female & $-16.50000^{*}$ & 6.94832 & .019 & -30.2620 & -2.7380 \\
& RO Female & -2.00000 & 6.94832 & .774 & -15.7620 & 11.7620 \\
\hline \multirow{2}{*}{ RO Female } & RP Female & $-14.50000^{*}$ & 6.94832 & .039 & -28.2620 & -.7380 \\
& RP Male & -12.50000 & 6.94832 & .075 & -26.2620 & 1.2620 \\
& RO Male & 2.00000 & 6.94832 & .774 & -11.7620 & 15.7620 \\
\hline
\end{tabular}

According to the results of the LSD test, there existed a significant difference between RP male and RO male $(\mathrm{sig}=.039<.05)$, RP female and RO female $(\mathrm{sig}=.039<.05)$ and RP female and RO male $(\operatorname{sig}=.019<.05)$; consequently, there was a significant difference between RP and RO groups in acquisition scores (Table 5).

Table 6. Test of homogeneity of variances

\begin{tabular}{lccc}
\hline Levene Statistic & $\mathrm{df1}$ & $\mathrm{df2}$ & Sig. \\
\hline .006 & 3 & 116 & .999 \\
\hline
\end{tabular}


Table 7. Results of ANOVA test on the retention scores

\begin{tabular}{lccccc}
\hline & Sum of Squares & df & Mean Square & F & Sig. \\
\hline Between Groups & 4031.400 & 3 & 1343.800 & 2.850 & .040 \\
Within Groups & 54702.600 & 116 & 471.574 & & \\
Total & 58734.000 & 119 & & & \\
\hline
\end{tabular}

According to table6, significance of Levene's Statistic was 0.999 (sig $>0.05$ ) in retention test, so test of the comparison of means with the assumption of homogeneity of variances was performed (Table 7). The significance between groups ( $\mathrm{RP}$ and RO treatments) on the retention scores was 0.040 ( $\mathrm{sig}<0.05$ ), so there existed a significant difference between groups on the retention scores; therefore, the hypothesis of homogeneity of means at 0.05 level was rejected, i.e., at least two groups out of the four participating groups had different means, so for specifying groups which had different means, LSD Test was performed (Table 8).

Table 8. LSD test for retention scores

\begin{tabular}{lcccccc}
\hline \multirow{2}{*}{ (I) Groups } & (J) Groups & Mean & \multirow{2}{*}{ Difference (I-J) } & Std. Error & \multirow{2}{*}{ Sig. } & \multicolumn{2}{c}{$95 \%$ Confidence Interval } \\
\cline { 6 - 7 } RP Male & RP Female & -2.00000 & 5.60698 & .722 & -13.1053 & 9.1053 \\
& RO Male & $11.50000^{*}$ & 5.60698 & .043 & .3947 & 22.6053 \\
& RO Female & 9.30000 & 5.60698 & .100 & -1.8053 & 20.4053 \\
\hline \multirow{3}{*}{ RP Female } & RP Male & 2.00000 & 5.60698 & .722 & -9.1053 & 13.1053 \\
& RO Male & $13.50000^{*}$ & 5.60698 & .018 & 2.3947 & 24.6053 \\
& RO Female & $11.30000^{*}$ & 5.60698 & .046 & .1947 & 22.4053 \\
\hline \multirow{3}{*}{ RO Male } & RP Male & $-11.50000^{*}$ & 5.60698 & .043 & -22.6053 & -.3947 \\
& RP Female & $-13.50000^{*}$ & 5.60698 & .018 & -24.6053 & -2.3947 \\
& RO Female & -2.20000 & 5.60698 & .696 & -13.3053 & 8.9053 \\
\hline \multirow{2}{*}{ RO Female } & RP Male & -9.30000 & 5.60698 & .100 & -20.4053 & 1.8053 \\
& RP Female & $-11.30000^{*}$ & 5.60698 & .046 & -22.4053 & -.1947 \\
& RO Male & 2.20000 & 5.60698 & .696 & -8.9053 & 13.3053
\end{tabular}

*. The mean difference is significant at the 0.05 level.

According to the results of the LSD test, there existed a significant difference between RP male and RO male (sig=.043<.05), RP female and RO female (sig=.046<.05), RP female and RO male $(\mathrm{sig}=.018<.05)$, so there was a significant difference between RP and RO groups in retention scores (Table8).

The means of the RP treatments on the acquisition and retention tests in male and female students was higher than that of the RO treatment (Appendix A). Statistically; it showed that dissimilarity between the two groups was high. Consequently, the results showed that the students got higher scores in the RP classes, the range of the RO, however, was higher than that of the RP, and it showed that the degree of variability of the scores in the RO groups wasmore than that of the RP groups in both males and females. So, reading comprehension with morevocabulary exercises led to more successful learning of vocabulary items than reading additional texts with the same words.

To answer the second research question (Do Iranian male and female EFL learners perform significantly different in learning vocabulary through these methods (RP vs. RO) in immediate acquisition and retention after three months period?), a one way ANOVA Test was conducted. The mean differences between the pre-test scores of males and females $(\mathrm{MD}=2.2$, sig $=0.666>0.05)$, acquisition scores of males and females $(\mathrm{MD}=2, \mathrm{sig}=0.693>0.05)$ and retention scores of males and females $(\mathrm{MD}=2.1, \mathrm{sig}=0.607>0.05)$ indicated that the dissimilarity between the mean scores of acquisition and retention tests in males and females was not statistically significant and there existed no significant difference between the results of male and female students in pre-test, acquisition and retention tests (Appendix A). 
Table 9. Test of homogeneity of variances

\begin{tabular}{llll}
\hline Levene Statistic & df1 & df2 & Sig. \\
\hline .018 & 1 & 118 & .894 \\
\hline
\end{tabular}

Table 10. Results of ANOVA test on the pretest scores in male and female students

\begin{tabular}{llllll}
\hline & Sum of Squares & $\mathrm{df}$ & Mean Square & $\mathrm{F}$ & Sig. \\
\hline Between Groups & 145.200 & 1 & 145.200 & .187 & .666 \\
Within Groups & 91454.800 & 118 & 775.041 & & \\
Total & 91600.000 & 119 & & & \\
\hline
\end{tabular}

According to Table 9, significance of Levene's Statistic was 0.894 (sig $>0.05)$ in pretest scores in males and females, so test of comparison of means with the assumption of homogeneity of variances was performed (Table 10). The significance between males and females on the pretest scores was 0.666 ( $\mathrm{sig}>0.05)$, so there existed no significant difference between males and females on the pretest scores.

Table 11. Test of homogeneity of variances

\begin{tabular}{llll}
\hline Levene Statistic & df1 & df2 & Sig. \\
\hline .050 & 1 & 118 & .823 \\
\hline
\end{tabular}

Table 12. Results of ANOVA test on the acquisition scores in male and female students

\begin{tabular}{lccccc}
\hline & Sum of Squares & df & Mean Square & F & Sig. \\
\hline Between Groups & 120.000 & 1 & 120.000 & .157 & .693 \\
Within Groups & 90313.300 & 118 & 765.367 & & \\
Total & 91600.000 & 119 & & & \\
\hline
\end{tabular}

According to Table 11, significance of Levene's Statistics was 0.823 (sig $>0.05$ ) in acquisition scores in males and females, so test of comparison of means with the assumption of homogeneity of variances was performed (Table 12). The significance between males and females on the acquisition scores was 0.693 (sig $>0.05$ ), so there existed no significant difference between males and females on the acquisition scores.

Table 13. Test of homogeneity of variances

\begin{tabular}{llll}
\hline Levene Statistic & df1 & df2 & Sig. \\
\hline .117 & 1 & 118 & .733 \\
\hline
\end{tabular}

Table 14. Results of ANOVA test on the retention scores in male and female students

\begin{tabular}{lccccc}
\hline & Sum of Squares & df & Mean Square & F & Sig. \\
Between Groups & 132.300 & 1 & 132.300 & .266 & .607 \\
Within Groups & 58601.700 & 118 & 496.625 & & \\
Total & 58734.000 & 119 & & & \\
\hline
\end{tabular}

According to Table 13, significance of Levene's Statisticswas 0.733 (sig $>0.05$ ) in retention scores in males and females, so test of comparison of means with the assumption of homogeneity of variances was performed (Table 14). The significance between males and females on the retention scores was $0.607(\mathrm{sig}>0.05)$, so there existed no significant difference between males and females on the retention scores. 
The results of the ANOVA Test indicated that there existed a significant difference between the two instructional treatments' results; however, the difference between the mean scores of males and females on acquisition and retention scores was not statistically significant; therefore, the answer to the first research question was positive while the second question's answer was negative, i.e., the RP groups gained better results than RO groups on both acquisition and retention tests. This indicated that "Reading plus" method is more effective in increasing knowledge of vocabulary and long term retention then the "Reading only" method, and the results of male and female students' performance on acquisition and retention tests via these methods was not significantly different.

\section{Conclusion}

The present study aimed at comparing the effectiveness of two instructional treatments (reading only and reading plus vocabulary- enhancement activities) on vocabulary acquisition and retention to explore how vocabulary learning can be improved more effectively. The main part of the research involved an instructional design approach, incorporating instructional intervention that may serve as a key for helping the learners. The results provided evidence to suggest that the RP approach increases vocabulary learning more than the RO approach. The present study showed that instructional intervention (RP approach) can be successfully used to improve EFL learners' vocabulary learning. This finding is practical for EFL vocabulary instruction. By using thesesupplemental vocabulary activities students are able to focus on special vocabularies and understand the meanings and functions of them and learn more vocabularies. Based on Gass (1988) classification theory, the findings also showed that the use of different vocabulary exercises can makesuccessful and varied encounters with target words in the RP group. In addition, the resultsclarified that teachers' expansionof lexical instruction would help students foster their vocabulary knowledge during a short period and focus on certain vocabularies for more practice. In conclusion, although reading for meaning appears to produce significant results in vocabulary learning, such reading supplemented with specific vocabulary exercises produces greater gains for the targeted words. This suggests that although instruction makes a difference, more focused instruction is desirable when the learning period is limited and specific vocabulary outcomes are sought.

\section{References}

Chen, C. M., \& Chun, C. J. (2008). Personalized Mobile English vocabulary Learning System Based on Item Response Theory and Learning Memory Cycle. Computers \& Education, 51(2), 624-645. http://dx.doi.org/10.1016/j.compedu.2007.06.011

Chun, D., \& Plass, L. J. (1996). Effects of multimedia annotation on vocabulary acquisition. The Modern Language Journal, 80, 183-195. http://dx.doi.org/10.1111/j.1540-4781.1996.tb01159.x

Coady, J. (1997a). L2 vocabulary acquisition: A synthesis of the research. In J. Coady, \& T. Huckin (Eds.), Second language vocabulary acquisition (pp. 225-237). Cambridge: Cambridge University Press.

Coady, J., \& Huckin, T. (1997b). Second language vocabulary acquisition. USA: Cambridge University Press.

Folse, K. S. (2004). The Underestimated Importance of Vocabulary in the Foreign Language Classroom. Retrieved January 27 , 2010 , from http://www.seasite.niu.edu/trans/articles/Underestimated\%20Importance\%20of\%20vocab.html

Gass, S. (1988). Integrating research areas: A framework for second language studies. Applied Linguistics, 9 , 233-252. http://dx.doi.org/10.1093/applin/9.2.198

Gass, S. (1988). Second language vocabulary acquisition. Annual Review of Applied Linguistic, 9, 92-106. http://dx.doi.org/10.1017/S0267190500000829

Hatch, E., \& Brown, C. (1995). Vocabulary, semantics and language education. Cambridge: Cambridge University Press.

Hedge, T. (2008). Teaching and learning in the language classroom. Oxford: Oxford University Press.

Herbertson, M. (2010). Lexis and Grammar. Retrieved November 8, 2009, from http://www.philseflsupport.com/grammarnlexis.htm

Krashen, S. (1989). We acquire vocabulary and spelling by reading: Additional evidence for the output hypothesis. The Modern Language Journal, 74, 440-464. http://dx.doi.org/10.1111/j.1540-4781.1989.tb05325.x

Laufer, B. (2003). Vocabulary acquisition in a second language: Do learners really acquire most vocabulary by reading? Some empirical evidence. The Canadian Modern Language Review, 59(4), 567-587. http://dx.doi.org/10.3138/cmlr.59.4.567 
Lyster, R. (1990). The role of analysis language teaching in French immersion programs. Canadian Modern Language Review, 47(1), 156-176.

Nagy, W. E., Herman, P., \& Anderson, R. C. (1985). Learning words from context. Reading Research Quarterly, 20, 233-253.

Nation, I. S. P., \& Coady, J. (1988). Vocabulary and reading. In R. Carter, \& M. McCarthy (Eds.), Vocabulary and language teaching (pp. 97-110). London: Longman.

Norman, C., \& Fowler, W. S. (1986). Nelson English language tests. Great Britain: Butler and Tanner Ltd.

Paribakht, T. S., \& Wesche, M. (1993). Reading comprehension and second language development in a comprehension-based ESL program. TESL Canada Journal, 11(1), 9-29.

Paribakht, T. S., \& Wesche, M. B. (1997). Vocabulary enhancement activities and reading for meaning in second language vocabulary development. In J. Coady, \& T. Huckin (Eds.), Second language vocabulary acquisition: A rationale for pedagogy (pp. 174-200). New-York: Cambridge University Press.

Richards, J. C., \& Renandya, W. A. (Eds.). (2002). Methodology in language teaching: An Anthology of current practice. Cambridge: Cambridge University Press.

Rott, S. (1999). The effect of exposure frequency on intermediate language learners' incidental vocabulary acquisition and retention through reading. Studies in Second Language Acquisition, 21, 589-619.

Shoebottom, P. (2007). How to learn a Vocabulary. Retrieved March 5, 2010, from http://esl.fis.edu/learners/advice/vocab.htm

Swain, M. (1988). Manipulating and complementing content teaching to maximize second language learning. TESL Canada Journal, 6(1), 68-83.

\section{Appendix}

Descriptive Statistics of the Scores

Descriptive Statistics of the Pretest Scores

\begin{tabular}{|l|l|l|l|l|l|}
\hline & \multicolumn{2}{|l|}{ Group } & N & Mean & Std.Deviation \\
\hline \multirow{3}{*}{ Pretest } & \multirow{2}{*}{ Male } & RO & 30 & 103.40 & 29.67 \\
\cline { 3 - 6 } & & RP & 30 & 98.40 & 27.04 \\
\cline { 2 - 6 } & Female & RO & 30 & 105.30 & 29.12 \\
\cline { 3 - 6 } & & RP & 30 & 100.90 & 25.90 \\
\hline
\end{tabular}

Descriptive Statistics of the Acquisition Scores

\begin{tabular}{|l|l|l|l|l|l|}
\hline & \multicolumn{2}{|l|}{ Group } & N & Mean & Std.Deviation \\
\hline Acquisition & Male & RO & 30 & 185.90 & 30.14 \\
\cline { 3 - 6 } & & RP & 30 & 200.40 & 23.68 \\
\cline { 2 - 6 } & Female & RO & 30 & 187.90 & 26.96 \\
\cline { 2 - 6 } & & RP & 30 & 202.40 & 26.48 \\
\hline
\end{tabular}

Descriptive Statistics of the Retention Scores

\begin{tabular}{|l|l|l|l|l|l|}
\hline & \multicolumn{2}{|l|}{ Group } & N & Mean & Std.Deviation \\
\hline \multirow{3}{*}{ Retention } & Male & RO & 30 & 146.20 & 21.46 \\
\cline { 3 - 6 } & & RP & 30 & 157.70 & 22.83 \\
\cline { 2 - 6 } & Female & RO & 30 & 148.40 & 21.12 \\
\cline { 2 - 6 } & & RP & 30 & 159.70 & 21.41 \\
\hline
\end{tabular}




\section{Descriptive Statistics of the Pretest Scores in Male and Female Students}

\begin{tabular}{|l|l|l|l|l|}
\hline & & N & Mean & Std.Deviation \\
\hline \multirow{3}{*}{ Pretest } & Female & 60 & 103.1000 & 27.41192 \\
\cline { 2 - 5 } & Male & 60 & 100.9000 & 28.26071 \\
\hline
\end{tabular}

Descriptive Statistics of the Acquisition Scores in Male and Female Students

\begin{tabular}{|l|l|l|l|l|}
\hline & & N & Mean & Std.Deviation \\
\hline Acquisition & Female & 60 & 195.1500 & 27.48 \\
\cline { 2 - 5 } & Male & 60 & 193.1500 & 27.85 \\
\hline
\end{tabular}

Descriptive Statistics of the Retention Scores in Male and Female Students

\begin{tabular}{|l|l|l|l|l|}
\hline & & N & Mean & Std.Deviation \\
\hline \multirow{2}{*}{ Retention } & Female & 60 & 154.05 & 21.84 \\
\cline { 2 - 5 } & Male & 60 & 151.95 & 22.72 \\
\hline
\end{tabular}

\section{Copyrights}

Copyright for this article is retained by the author(s), with first publication rights granted to the journal.

This is an open-access article distributed under the terms and conditions of the Creative Commons Attribution license (http://creativecommons.org/licenses/by/3.0/). 